\title{
Influencing Factors of Online Shopping for Young Consumers based on SEM Model
}

$$
\text { Li yongqing }{ }^{1} \text {, a, Ma li }{ }^{2} \text {, b }
$$

${ }^{1}$ School of management, Xi 'an university of science and technology, Xi 'an, China

${ }^{2}$ School of management, Xi 'an university of science and technology, Xi 'an, China

a email: 642079821@qq.com

b email: 642079821@qq.com

${ }^{*}$ Corresponding author:Ma li

Keywords: Young consumers; Network shopping; Model of structural equation; Purchase intention

\begin{abstract}
With the construction of "One Belt And One Road" in China, more and more people are beginning to participate in online consumption. However, the complexity of consumption in the online environment becomes the main reason for the network shopping. Based on the hypothesis model of brand image and service quality, this paper use factor analysis and structural equation model to verify the hypothesis. The results show that the brand image, service quality, technical security and logistics service of shopping platform can affect consumer trust and satisfaction. The risk perception of shopping also affects the willingness of consumption.
\end{abstract}

\section{基于 SEM 模型青年消费者选择网络购物的影响因素测度}

\author{
李永清 $1, a$,马莉 $2, b$ \\ 1 西安科技大学管理学院, 陕西, 西安, 中国 \\ 2 西安科技大学管理学院, 陕西, 西安, 中国 \\ a 邮箱: 642079821@qq.com \\ b 邮箱: 642079821@qq.com \\ *通讯作者：马莉
}

关键词：青年消费者；网络购物；结构方程模型；购买意愿

中文摘要.网络购物因 “一带一路” 建设影响日趋深远, 越来越多的人开始加入到网络购物中 去。鉴于网络购物通常会受网络环境消费复杂性的束缚, 本文通过建立品牌形象、服务品质 等变量的假设模型, 采用因子分析和结构方程模型验证假设。研究结果发现: 网络购物平台 的品牌形象、服务品质、技术安全、物流服务等都会影响消费者信任及满意度从而而影响消 费意愿；对网络购物的风险感知也会影响消费意愿。

\section{1. 引言}

网络购物自身有着不可比拟的便捷优势, 该购物模式已经成为门店消费的重要互补方式。 Thornton ${ }^{[1]}$ 研究发现网络商店获得持续竞争优势的核心是有效利用网络和信息技术系统构建 的顾客关系。Koufaris 和 Hampton-Sosa ${ }^{[2]}$ 认为影响网络销售交易信任的因素包括交易安全、 网站功能、消费者的满意度。青年作为使用网络的主要群体, 对该群体进行网络购物研究具 有代表性。综上述，本文以“一带一路”建设环境下的网络购物情况为研究背景，探索影响青 
年消费者网络购物的影响因素，对网络购物平台的完善搭建起到一定的建议作用。

\section{2. 研究模型与假设}

\section{1 研究模型}

网络消费群体只需浏览产品页面, 将心仪产品下单就能实现网络购物。因此, 若想发挥 网络销售中的竞争优势, 就必须对网络消费群体有明确认知。本文根据学者研究基础上, 重 点分析网络购物中的青年群体, 提出基于青年消费者选择网购意向的模型框架, 如图 1 所示:

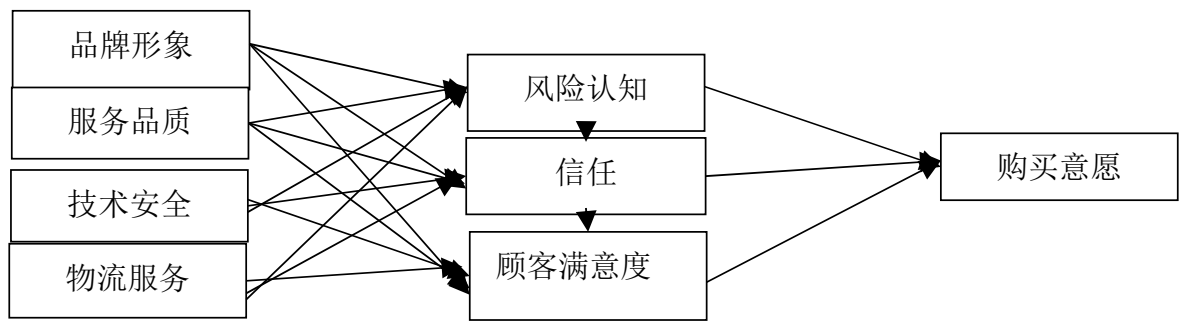

图 1 青年学生选择网络购物意愿影响因素模型

\section{2 研究假设}

\subsection{1 品牌形象与网络购物信任的关系}

消费者在产品信息掌握不全的情况下，购买决策会受到信任的影响。Overby ${ }^{[3]}$ 的研究表明 购物网站可通过建立品牌形象、提升服务品质、保证购物环境的技术安全等增强消费者对该 购物网站的信任从而提升竞争能力。因此, 可以提出以下假设:

假设 1：消费者的信任受到网购购物平台品牌形象的正向影响

2.2.2 网络购物平台服务品质与消费者信任的关系

网络购物受到购物网站提供的咨询服务、退换货、维修等因素影响。Cho 和 Park ${ }^{[4]}$ 选择 了网络销售商提供的产品信息、顾客服务、售后服务、付款方式等作为衡量顾客选择网络消 费的评价项目。因此提出以下假设:

假设 2：购物网站服务品质正向影响消费者信任

\subsection{3 购物网站技术安全与网络购物消费者信任的关系}

Szymanski 和 Hise ${ }^{[5]}$ 把产品信息、网站设计和交易安全等因素作为信任的前置因子, 通过 实证研究确定这些因子对顾客信任有正向作用。因此, 可以提出以下假设:

假设 3：技术安全正向影响消费者对网络购物的信任。

\subsection{4 购物网站物流服务与网络购物消费者信任的关系}

顾客会根据配送速度，运输情况及服务选择网络购物模式。Joong-Kun ${ }^{[6]}$ 对网络消费环境 中物流能力的研究结果表明, 物流能力在网络购物选择中起着重要作用。因此提出以下假设:

假设 4: 消费者网络购物的信任受到物流服务的正向影响。

2.2 .5 网络购物消费者信任与感知风险的关系

风险感知、风险决策及风险与信任的关系在经济学中都有过深入研究。消费者对网络购 物的信任程度受到对风险感知大小的影响得到诸多学者认可。因此, 可以提出以下假设:

假设 5: 网络消费者对网络购物的信任受到风险感知的负向影响

假设 6: 网络消费者网络购物的消费意愿受到风险感知的负向影响

假设 7: 网络消费者对购物网站的信任正向影响消费者购买意愿

\section{3 消费者信任与顾客满意的关系}

提高顾客满意度是留住顾客消费的基本方式之一。若能提升顾客满意度增强顾客信任, 对网络购物平台的完善有着重要作用。因此, 提出如下假设:

假设 8：消费者对网站的信任正向影响消费满意度。 
假设 9: 消费者对网络消费的满意度会正向影响消费意愿。

\section{3. 问卷设计与数据收集}

\section{1 问卷设计}

对近年国外该研究领域的期刊论文进行篮选，对常用量表加以分析综合，结合国内实际 情况及相关文献进行必要修正。品牌形象主要借鉴 LeBlance and Nguyen ${ }^{[7]}$ 的量表; 网站的服 务品质和技术安全借鉴 Flavian ${ }^{[8]}$ 量表; 选择 Joong-Kun ${ }^{[6]}$ 的量表衡量物流服务。问卷采用李克 特（Likert） 5 点量表， 1 代表“非常不同意”，5 代表“非常同意”。调查问卷项如表 1 所示:

\section{2 数据收集}

研究采取调查问卷方式，考虑到研究主体是青年学生，所以调查对象选取 250 名在校大 学生、研究生、博士等青年群体。数据处理采用表列删除的方法。本次调查共计收回 223 份 有效问卷, 均是在过去半年有网络消费经历的, 问卷有效率 $89 \%$, 符合统计标准。参与填写 问卷的人群有来自北京、辽宁、甘肃、西安、山东等省市，保证了数据的广泛性。

\section{4. 数据分析}

\section{1 数据的信度检验}

学者们普遍承认 Cronbach $\alpha$ 系数检验数据的可靠性。通常情况下, $\alpha>0.7$ 则说明该组统 计数据有较强的信度水平, 可用来衡量研究变量的信度情况。经 SPSS 17.0 的可靠性检验结 果显示, 品牌形象、品质服务、技术安全、物流服务等的 $\alpha$ 系数均大于 0.7 , 所以该问卷信度 水平较好。信度检验结果如表 1 所示。

表 1 青年学生选择网络购物的影响因素的调查问卷信度检验

\begin{tabular}{|c|c|c|}
\hline 变量 & 测量问项 & Cronbach $\alpha$ 系数 \\
\hline 品牌形象 & $\begin{array}{l}\text { 1.电商企业与媒体的宣传 } \\
\text { 2.电商企业的社会责任感 } \\
\text { 3.电商企业的特色化形象 } \\
\text { 4.电商企业的创新能力 }\end{array}$ & 0.895 \\
\hline 服务品质 & $\begin{array}{l}\text { 1.网络购物选择范围广泛 } \\
2 \text { 与供应商沟通方便 } \\
\text { 3.客服态度良好 } \\
\text { 4.退换货容易 }\end{array}$ & 0.846 \\
\hline 技术安全 & $\begin{array}{l}\text { 1.人性化的网站设计 } \\
\text { 2.访问系统便捷容易 } \\
\text { 3.个人隐私保护全面 } \\
\text { 4.支持多种支付方式 }\end{array}$ & 0.839 \\
\hline 物流服务 & $\begin{array}{l}\text { 1..线下物流运输速度 } \\
\text { 2.取快递容易 } \\
\text { 3.物流运输安全 } \\
\text { 4.物流服务态度 }\end{array}$ & 0.776 \\
\hline 风险感知 & $\begin{array}{l}\text { 1.网络环境下银行卡信息安全 } \\
\text { 2.网络购物质量有风险 } \\
\text { 3.购物商店有信誉认证 } \\
\text { 4.购物网站能实现承诺 }\end{array}$ & 0.899 \\
\hline 信任 & $\begin{array}{l}\text { 1.相信网店商品质量有保障 } \\
\text { 2.相信网店能提供良好的售后服务 } \\
\text { 3.相信网店提供的产品信息安全 } \\
\text { 4.相信网络购物有他的自身优势 }\end{array}$ & 0.749 \\
\hline
\end{tabular}




\begin{tabular}{c|l|c}
\hline & $\begin{array}{l}1 . \text { 购物体验令我满意 } \\
\text { 2.购物的方便快捷令我满意 }\end{array}$ & 0.876 \\
\hline 满意程度 & $\begin{array}{l}\text { 1.如果有购物需求, 会首选网络购物 } \\
\text { 2.愿意在网站上选择再次消费 }\end{array}$ & 0.918 \\
\hline 购物意愿 & .
\end{tabular}

\section{2 数据的效度检验}

通常情况下, 数据适合做因子分析的 KMO 值越接近于 1, 本文样本经过 SPSS 检验 KMO 值为 0.719 , 则适合做因子分析且效果较好。Sig. $<0.05$ 说明各变量间具有相关性, 因子分析有 效。本文 Sig. 值为 0.000 小于显著水平, 说明变量间具有相关关系, 适合做因子分析。 KMO 和 Bartlett 检验结果如表 2 所示。

\begin{tabular}{|c|c|c|}
\hline \multicolumn{2}{|c|}{ KMO } & 0.719 \\
\hline \multirow{3}{*}{ Bartlett's 检验 } & 卡方值 & 3511.915 \\
\hline & 自由度 & 378 \\
\hline & Sig. & 0.000 \\
\hline
\end{tabular}

经过分析旋转成分矩阵, 篮选出大于 0.5 的因子载荷。经整理, 各问项归类符合期望, 且每个观察变量的因子载荷均符合建议水平大于 0.5 , 表明此量表整体的收玫效度较好。旋转 成分矩阵如表 3 所示。

\begin{tabular}{|c|c|c|c|c|c|c|c|}
\hline & \multicolumn{7}{|c|}{ 成分 } \\
\hline & 1 & 2 & 3 & 4 & 5 & 6 & 7 \\
\hline 企业与媒体宣传 & 0.799 & & & & & & \\
\hline 社会责任感 & 0.789 & & & & & & \\
\hline 特色化形象 & 0.803 & & & & & & \\
\hline 创新能力 & 0.798 & & & & & & \\
\hline 选择范围广泛 & & 0.803 & & & & & \\
\hline 沟通方便 & & 0.794 & & & & & \\
\hline 客服态度 & & 0.827 & & & & & \\
\hline 退换货容易 & & 0.831 & & & & & \\
\hline 人性化网站设计 & & & 0.861 & & & & \\
\hline 访问系统便捷 & & & 0.796 & & & & \\
\hline 个人隐私保护 & & & 0.853 & & & & \\
\hline 支持多种支付 & & & 0.764 & & & & \\
\hline 物流速度 & & & & 0.730 & & & \\
\hline 取快递方便 & & & & 0.808 & & & \\
\hline 物流运输安全 & & & & 0.766 & & & \\
\hline 物流态度 & & & & 0.778 & & & \\
\hline 银行卡信息安全 & 0.828 & & & & & & \\
\hline 质量风险 & 0.792 & & & & & & \\
\hline 网店信誉认证 & 0.807 & & & & & & \\
\hline 网店承诺 & 0.856 & & & & & & \\
\hline 质量保障 & & & & & 0.737 & & \\
\hline 售后服务 & & & & & 0.754 & & \\
\hline 产品安全 & & & & & 0.746 & & \\
\hline 网店有自身优势 & & & & & 0.765 & & \\
\hline 购物体验 & & & & & & & 0.926 \\
\hline 购物方便快捷 & & & & & & & 0.925 \\
\hline 首选网络购物 & & & & & & 0.940 & \\
\hline 选择再次消费 & & & & & & 0.954 & \\
\hline
\end{tabular}

\section{3 模型假设检验}


由于研究内容是网络购物意愿, 不能直接被观测, 所以采用一些观察变量来反应潜变量。 结构方程模型在处理潜变量方面有着自身优势, 因此特采用结构方程模型分析影响青年学生 网络购物的因素。采用 AMOS21.0 建立研究模型并进行验证分析, 结构模型如图 2 所示。

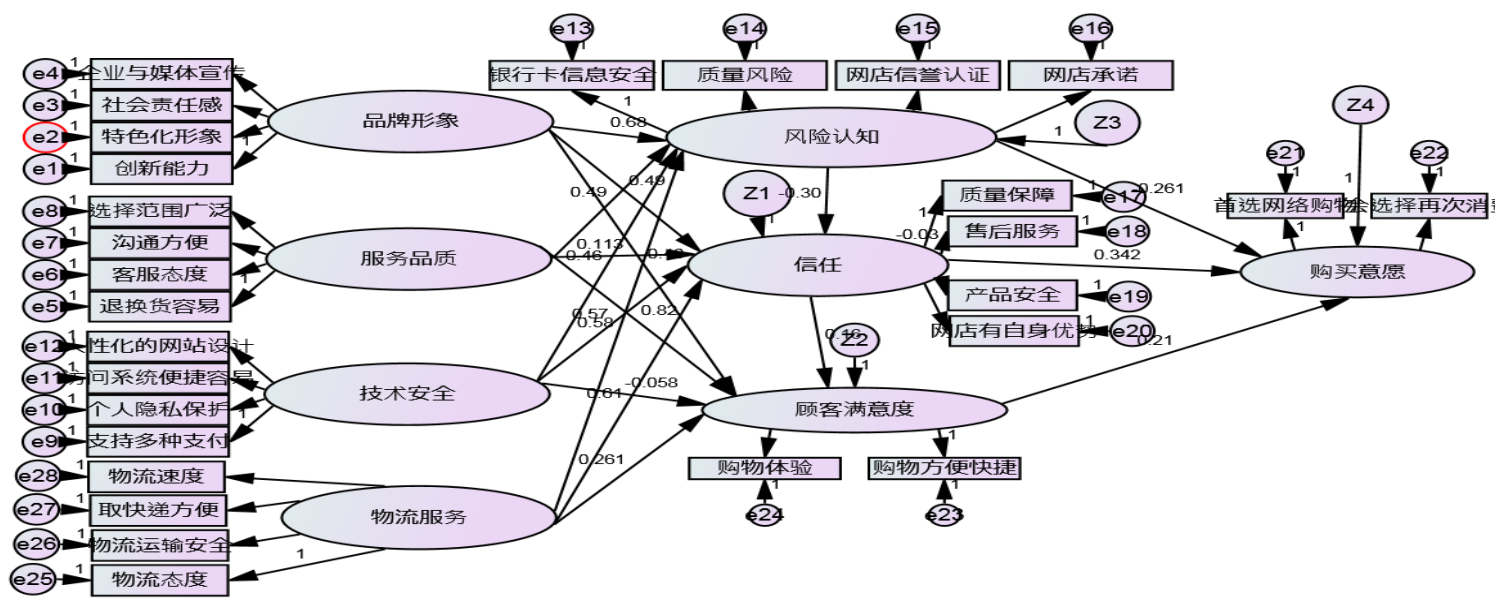

图 2: 青年消费者消费模型假设检验结果

（1）模型构成及结构方程模型拟合指标。经整理得到观测变量 28 个。其中 4 个模型外 生潜变量, 分别是：网络购物平台的品牌形象、服务品质、技术安全、物流服务。每一个外 生潜变量都使用 4 个观测变量测量。内生潜变量共计 4 个, 分别是：青年消费者对网络购物 的风险认知、信任情况、满意程度以及购买意愿。

根据分析结果可知结构方程拟合情况: $\chi^{2} / d f<3$, 平均近似值误差平方根 (RMSEA) $<0.08$, 拟合度指标 (GFI)、规范拟合指标 (NFI)、比较拟合指标 (CFI) 等均满足大于 0.9 的要求。经检验, 型整体拟合度较好, 满足要求。青年学生选择网络购物结构方程模型的拟合 指标情况如表 4 所示。

表 4：结构方程模型的整体拟合指标

\begin{tabular}{c|c|c|c}
\hline 拟合指标 & 指标值 & 参考值 \\
\hline \multicolumn{2}{|c|}{ 模型绝对拟合度 } & 检验结果 \\
\hline Discrepancy/df & 2.088 & $<3$ & 满足 \\
\hline 拟合度指标 (GFI) & 0.931 & $>0.9$ & 满足 \\
\hline 近似均方根 (RMSEA) & 0.069 & $<0.08$ & 满足 \\
\hline 规范拟合指数 (NFI) & 0.902 & $>0.9$ & 满足 \\
\hline 比较拟合指标 (CFI) & 0.985 & $>0.9$ & 满足 \\
\hline
\end{tabular}

（2）结构方程模型假设检验。经检验，品牌形象对信任网络购物的路径系数为 0.48 , 假 设 1 得到检验, 说明消费者对网络购物的信任受到品牌形象的正向影响。购物网站的服务品 质对信任网络购物的路径系数为 0.213 , 假设 2 得到检验, 说明青年网络消费者的信任受到网 站服务品质的正向影响，因此需要积极提升网站服务品质促进网站盈利。网络购物平台技术 安全对青年消费者信任的路径系数为 0.57 , 假设 3 得到检验。物流服务对信任的路径系数为 0.06, 未达到显著水平，假设 4 不通过，说明青年消费者对网络购物的信任不能通过物流服 务增强。经访谈研究发现, 造成这一结果主要是因为青年消费者选择网络购物时, 对物流的 关注并不明显, 如果认定网店值得信任, 青年群体还是会选择网络购物行为。感知风险对青 年消费者信任网络购物的路径系数为 -0.30 , 假设 5 得到检验。感知风险对消费意愿的路径系 数为 -0.261 , 说明随网络购物的风险感知提高青年学生群体购物意愿降低, 这体现青年消费群 体会因网络购物网站的风险而放弃该购物选项。信任对网络购物意愿的路径系数为 0.342 , 假 设 6 得到检验, 说明青年网络消费群体的购物意愿受到对网络购物平台信任的正向影响。信 
任对顾客满意程度的路径系数仅为 0.16 , 假设 7 未得到支持。通过访谈调查发现, 信任相比 服务品质、技术安全等对青年网络消费者满意程度影响较弱。顾客信任对满意的路径系数为 0.48 , 假设 8 得到检验。顾客满意对购买意愿的路径系数为 0.21 , 假设 9 得到检验。

\section{5. 结束语}

本文实证研究了影响青年消费者选择网络购物的因素。通过分析，购物网站的品牌形象、 技术安全等指标会通过影响青年消费群体的信任和满意度, 影响消费者选择。风险认知也会 作为信任的前因变量影响青年网络消费群体的购物意愿。基于以上实证分析的启示，可以对 我国电子商务发展以及电商企业提出以下建议: 树立品牌形象, 保证购物环境的技术安全, 提高服务品质、完善物流服务。

相比传统研究，本文样本限定在青年网络消费群体，更具严谨性。鉴于作者能力，本研 究仍有很多缺陷, 会在后续研究中不断完善。

\section{References}

[1] Thornton J,Marche S. Sorting through the dot bomb rubble: how did the high-profile e-tailers fail?[J].International Journal of Information Management, 2003, 23(2):121-138.

[2] Alon H, Liat E.The development of initial trust in an online company by new customers[J]. Information \& Management, 2004, 41(3):377-397.

[3] Lee EJ, Overby J W. Creating value for online shoppers: Implications for satisfaction and loyalty[J]. Journal of Consumer Satisfaction Dissatisfaction \& Complaining Behavior, 2004, 17.

[4] Cho N, Park S. Development of electronic commerce user-consumer satisfaction index (ECUSI) for Internet shopping.[J]. Industrial Management \& Data Systems, 2001, 101(8):400-406.

[5] Szymanski DM, Hise R T. E-satisfaction: an initial examination[J]. Journal of Retailing, 2000, 76(3):309-322.

[6] Cho JK. Firm performance in the e-commerce market: the role of logistics capabilities and logistics outsourcing[J]. 2001.

[7] Nguyen N, Leblanc G. Corporate image and corporate reputation in customers' retention decisions in services[J]. Journal of Retailing \& Consumer Services, 2001, 8(4):227-236.

[8] Flavian C, Guinaliu M, Gurrea R.The role played by perceived usability, satisfaction and consumer trust on website loyalty[J].Information and Management,2006,43(1):1-14 